\title{
Feminist Pandemic Pedagogies: Podcasting and the Study of Religion
}

\author{
Lee-Shae S. Scharnick-Udemans ${ }^{1}$ \\ lscharnickudemans@uwc.ac.za
}

\begin{abstract}
In this article I will explore and share my pedagogical practices and experiences as a feminist scholar of religion, within the context of a voluntary postgraduate reading group, during the first nine months of the Covid-19 pandemic. The article is structured in two parts. The first part offers a reflection of the teaching approaches that inspired and enabled the production of a podcast about the study of religion from the perspective of black African students and scholars of religion. The second part conceptualizes the production of a podcast as a feminist pedagogical experiment and reflects on this process alongside feminist pedagogical principles. While the orientation of this article is tentative and reflexive, it advances the argument that because of the commitment to social justice that is inherent to feminist approaches to scholarship and pedagogy, feminist scholars are generally poised to work within the contexts of crisis. Therefore, within the context of the pandemic, feminist approaches to teaching and learning in the study of religion may yield insights that can contribute to the continued development of sustainable pedagogies that honor the fraught nature of these times for both scholars and students.
\end{abstract}

1 This work was partially supported by the National Research Foundation of South Africa under the auspices of the author's Thuthuka Grant (Grant Number: 121945) and the Desmond Tutu Chair in Religion and Social Justice (Grant Number: 118854). The opinions, findings, and conclusions or recommendations expressed in the research are those of the author alone. The NRF accepts no liability in this regard. 
Keywords: Feminist pedagogy, knowledge production, podcasting, remote learning

\section{Introduction}

In the early days of the pandemic, social media were awash with memes that parodied the frightening accuracy and overuse of the term 'unprecedented' to describe the experience of living in a global public health crisis that qualifies as a pandemic. One meme, specifically related to academic experiences, shows the well-intentioned professor, offering what can be referred to as the pandemic disclaimer. The fictitious professor offers his acknowledgement of the unprecedented nature of the current situation, and then returns to business as usual, assigning tasks and uploading lecture materials to e-learning portals. On the other side of this meme are wild-eyed, overwhelmed students, pulling at their hair and biting their nails. The point of this meme as an expression of both offline and digital cultures, is that while the term 'unprecedented' is an accurate descriptor, it obscures the very real feelings of fear, grief, violence, loss, and uncertainty that color the current context. This meme also offers scholars of religion the opportunity to consider how the pandemic has shifted our own pedagogical practices and orientation towards students.

Covid-19 as an ongoing public health crisis has indisputably changed how we connect, teach, and learn across time and space. As international borders closed and cities were locked down, so were workplaces and classrooms of all varieties. Educators and students at every level of education from preschool to $\mathrm{PhD}$ were faced with the urgent and unexpected imperative to move from classroom-based teaching to online learning environments. The shift to remote learning is loaded with a range of technological and psychosocial challenges for both educators and learners and for the processes of teaching and learning.

For example, the mandate to work and study from home drove an abrupt collision of the private and the public, the personal and the professional, and highlighted the many and major inequalities that characterize our societies and the world. During the hard lockdown in South Africa, where gender-based violence was already a national crisis, there was a sharp rise in reported cases (Newham \& Du Plessis 2020). The isolation that social distancing required, enhanced opportunities for abuse to take place and 
further limited options for victims to find relief and recourse. Clark (2020:1) describes this marriage of crises as a 'clash of pandemics'. The point here is to acknowledge that domestic spaces and the notion of home are neither neutral nor universal.

The pandemic has disabused the notion that online space is anywhere and everywhere. The constitutional mobility that epitomizes the fundamental makeup of digital media technology and practices has been abrogated by the situatedness that the pandemic has enforced. The notion of being online has been relieved of its abstracted nature, and the online space and the domestic space have become synonymous. The vulnerabilities and inequities of the domestic space have long been subjected to critique by feminist scholars. Within the first few months of the pandemic, researchers offered emerging evidence supporting the postulation that Covid-19 has intensified the inequalities that typify the gendered division of domestic labor (Reichelt, Makovi, \& Sargsyan 2021; Meraviglia \& Dudka 2020).

In early March 2020, British journalist, Helen Lewis analyzed the asymmetrical, gendered expectations of caring responsibilities, including the care of children between men and women, and declared the Coronavirus 'a disaster for feminism' (Lewis 2020). Additionally, she postulated that a 'pandemic magnifies all existing inequalities' (Lewis 2020). While Lewis' sentiments ring true, an intersectional feminist approach offers a more expansive and nuanced perspective of the implications of Covid-19 on human existence and experiences. It considers how, together with gender, 'intersections of racism, patriarchy, ableism, and heteronormativity (among other axes of social power)' converge to produce complex systems of power and privilege, inclusion and exclusion, and within the specificity of the pandemic, risk, and consequence (Berkhout \& Richardson 2020:2). More recently, calls for vaccine solidarity have highlighted the exacerbation of inequalities within and between nations (Fidler 2020; Ho \& Dascalu 2020).

At the beginning of the global migration to remote learning, a group of feminist scholars, experienced in online pedagogies, working at the intersections of technology and science under the collective FemTechNet, offered a comprehensive set of guidelines for educators to consider during the upheaval of this pedagogical and technological migration (Juhasz, Wexler, Losh, \& Irish 2020). Being a feminist pandemic pedagogical manifesto of sorts, it is a well-considered and useful document for any educator. The authors show that the psycho-social aspects of the transition must be 
managed with the same care as the technical features. Most students and educators were not prepared for this epic migration to emergency remote learning. A reading of this guide, however, points to the possibility that, while these were in fact unprecedented times, feminist educators, particularly those employing social justice pedagogies, may have been more prepared for the challenges produced by the remote learning and work from home mandates, generated by the pandemic ${ }^{2}$.

The first part of this article describes the feminist pedagogical principles which informed the processes of the production of a podcast about the study of religion from the perspective of black African students and scholars of religion. This group of diverse individuals, all with different research interests, shared a commitment to the decolonial, intersectional, and feminist study of religion in Africa, and over the course of nine months met virtually bi-weekly to discuss various texts. Later on, the group would decide to capture its conversations in the form of podcasts. These conversations were recorded, edited, and sorted in order to comprise a set of audio files containing only verbal text, that were arranged in an episodic format which could digitally be circulated and downloaded on personal devices. While the production of the podcast took place synchronously, the podcast itself is asynchronously available. The second part describes the development of the podcast within the context of this reading group. Before turning to the first part of this discussion, I offer a brief comment on epistemological subjectivity and diversity in order to further contextualize the possibilities and limitations of researching, teaching, and learning during a pandemic.

2 I am cognizant of the established discourses and practices associated with pedagogies of care, and recognize the overlap between pedagogies of care and feminist pedagogies. Pedagogies of care require that the instructor takes the role of caregiver, while the student takes the role of care-receiver (Walker-Gleaves 2019). I have chosen to work primarily with feminist pedagogy and research practices as terms of reference because it encompasses many important strategies for care as pedagogy in institutional settings and also deliberately questions the assumptions and intersections of power and privilege that may color a framework of care. 


\section{Positionality and Reflexivity in a Pandemic}

Eighty days after the first reported case of Corona and in the wake of the announcement by the World Health Organization that Covid-19 had been declared a global pandemic, a professor of Applied Sciences at Zagreb University, Peter Jandrić made the following statement, 'While doctors, nurses, politicians, food suppliers, and many other brave people self-sacrifice to support our daily survival, this editorial argues that academics have a unique opportunity, and a moral duty, to immediately start conducting indepth studies of current events' (Jandrić 2020:234). This presumably wellintentioned statement is peppered with many disclaimers and underwritten by a distinctly nervous tone. It was made at a time of panic and urgency and perpetuates the problematic perception that researchers - as a result of our 'professional armor' which includes a 'carefully constructed public self as mysterious, impartial outsider[s]' - are somehow less affected by the multitudinous upheaval caused by the pandemic (England 1994:82).

The pandemic was not just happening around us; it was also happening to us. While Jandrić was able to use this time to dive into predicting, postulating, and producing knowledge about the implications of Covid-19, like many colleagues and acquaintances, I was not. Days after Jandrić would issue this call in March 2020, my family and I would be in quarantine due to my exposure to the virus. Unfortunately, testing in South Africa was not widely available at the time and while I showed no symptoms and did not become ill, I spent 14 anxious days expecting the worst. After experiencing the deaths of a handful of family members, neighbors, and acquaintances, it would take more than eight months of distance from my own recovery from Covid-19 which I contracted in August 2020, in order to try to study any aspect of the current context from an academic perspective.

Reflections on positionality, and subsequent practices of reflexivity in research are often primarily associated with the practice of fieldwork and are fundamental to thinking about pedagogical practices, including pedagogies of social justice. Feminist researchers have long emphasized the importance of reflexivity for understanding the way that power is constituted in the field projected by the researcher, and the possibilities of its mitigation through deliberate action ${ }^{3}$. Even in the case of non-empirical work that does not rely on human participants, a reflection on positionality and reflexivity

3 For more information, see Wigginton and Lafrance (2019). 
subverts the notion of the unbiased research observer and allows for greater insight into the epistemological orientation of the researcher and the research. Unfortunately, despite the utility of this practice for building an animated understanding of knowledge claims, it is still largely considered a practice reserved for those working in the area of gender and social justice.

Furthermore, if we are to make sense of our scholarship during this time, we cannot maintain the veneer that, as scholars we are first immune to the non-academic aspects of Covid-19 and second, to presume that our experiences and challenges during these times are all similar or equal. The possibilities and impossibilities for the production of knowledge about religion (and any other subject) are necessarily contingent regarding the ways in which the pandemic has affected us on a professional and personal level. As a result of this, a critical awareness of the intersectional situatedness of the researcher and the research is pertinent. Despite the problematic nature of his initial claim, Jandrić and a colleague produced a small creative project where a call was issued for researchers to send captioned pictures of their homework spaces. In the style of Instagram posts, the captions and pictures offered insight into how 81 academics from around the world were coming to terms with the mandate to work and teach from home. I want to follow Jandrić and Hayes (2020) and offer a brief caption, sans a photograph of my work from home space and experience:

I write this from a corner in my bedroom where I have managed to squeeze a desk. My partner works in the next room, and together we try to entertain our three-year-old son. We make playdough from scratch, set up sensory boxes and allow him to watch way too much television. During this time, the said three-year-old decides to potty train himself and the floor is almost always wet. Every day we cook, we clean, we care, I cry, we work.

I am a mother, partner, and woman of color. I am also an academic situated in a research center for the study of religion and social justice, at a historically black university. In response to the university's request for a continuity of activities plan, on the first day of the national lockdown, the director of the center, leading scholar of religion and gender, Prof Sarojini Nadar sent the following message to a WhatsApp group for staff and student employees of the Centre: 
1. We will continue to work with courage and compassion.

2. We will continue to work remotely with due consideration to the emotional upheaval that some experience in these moments of isolation.

3. We will step up to the plate when others cannot, with full knowledge that they will step up to the plate for us when we cannot.

4. We will work with common purpose and vision towards each of our tasks, and work with the principles of reciprocity, fairness and equity in mind (Desmond Tutu Annual Report 2020:2).

Like Juhasz et al. (2020) from FemTechNet, the feminist orientation of Nadar's leadership was displayed very early on in the pandemic and set the tone for a socially just approach to teaching and learning during a time of crisis. Although not universally agreed upon as public health crises, sexism, racism, gender-based violence, homophobia, transphobia, and ableism do have life and death consequences. These categories of human experiences have had the sustained academic attention of feminist scholars. Feminist scholars are trained and experienced to ethically, rigorously, and flexibly manage teaching and learning about these topics and within the contexts of crisis that these issues produce ${ }^{4}$. While the catastrophic and urgent nature of the pandemic was truly unprecedented, its underlying demand for approaches to teaching and learning strategies that heeded the situatedness of both educators and students, was familiar ground for feminist pedagogues.

Like many other universities, my home institution implored academics to show students that we care and will support them during and beyond the transition to online learning. We were urged to exercise flexibility in teaching, assessment, and examination and to be guided by the principle of 'no student left behind'. While I am not claiming that feminist pedagogues have held the monopoly of student care, I agree with Pelser (quoted in Ali, Watts Belser, Kao, \& Smith 2020:112) when she asks,

[W]hy have these same acts of respect and recognition not been available to students who have long been grappling with intense challenges whose impact all-too-often goes unrecognized? When my

4 For more information, see Hames (2016) and Bhana, Morrell, Shefer, and Ngabaza (2010). 
students have experienced mental health crises, when they have grappled with the brutal intersection of pervasive racism and ableism, when they have been hospitalized or institutionalized, when they have been wracked by grief or loss during a semester - has this same recognition about the urgency of care, this naming of care as the highest priority, been so clear? I think not. I have often tried to leverage my own institutional position to protect students from these external pressures, to try to offer them some shelter amid crisis especially a student whose crisis is 'taking too long' to subside, whose mental health needs are becoming 'too much', or who is at risk of being told they're out of time to 'get it together'.

Ironically through these calls for care and concern, albeit not named as such, feminist pedagogy and pedagogies of care which are often assigned to women, have achieved a level of mainstream acceptance because of its newfound utility for serving the needs of the privileged (Pelser quoted in Ali 2020; Moorhouse \& Tiet 2021; Rose \& Adams 2014).

\section{Teaching Practices: Feminist Pedagogies}

This section discusses the underlying principles that have undergirded my teaching practices as a feminist scholar of religion whose main area of research is not gender-related. My identification as a feminist scholar is indicative of the possibilities that a feminist pedagogy offers beyond the specificity of subject matter. Noting the vast and varied articulations of feminism and feminist pedagogies that exist within the various disciplines that comprise the academy, in a comprehensive multi-disciplinary literature review, Lynne Webb, Myria Watkins Allen, and Kandi Walker (2002:70-71) offer six basic principles of feminist pedagogy that apply across disciplines:

- Reformation of relationship between professor and students.

- Empowerment.

- Building community.

- Privileging the voice of the individual as a way of knowing.

- Respect for the diversity of personal experience.

- Challenging traditional views. 
My own understanding of feminist pedagogy ${ }^{5}$ as a set of orientations, principles, beliefs, and practices about and towards teachings and research, content, epistemology, and power, is informed by a variety of intersectional theories about feminism, critical theory on religion, as well as my lived experiences of mentorship as a student and an emerging academic. The principles listed above are lapstrake and act as a guideline for how I understand my purpose as a pedagogue. The reformation of the relationship between professor and student begins with the recognition of power and relies on a shared commitment to deliberately and creatively challenge that power. In this way, feminist pedagogy challenges traditional, hierarchical ways of teaching, learning, and being in the classroom. As Webb et al. (2004: 416) argue, 'Power becomes shared as students assume more responsibility for teaching and teachers for learning'. The practice of empowerment is closely related to the reformation of the relationship between professor and student. Here I take the definition of empowerment from one of the earliest theorists of feminist pedagogy, Carolyn Shrewsbury (1987:8) who explains that 'feminist pedagogy embodies a concept of power as energy, capacity, and potential rather than as domination'. In my teaching practices the process of building community is ongoing because it reflects a commitment to teaching and learning values, collective participation, and decision-making. In accepting the contested, contextual, and culture-bound character of knowledge as a feminist scholar, the classroom spaces that I create, seek to privilege the voice of the individual student as a valued site of knowledge. In modelling both acknowledgment of and appreciation for the diversity of personal experience, a democratic classroom environment nurtures the affirmation of the position that personal experience may constitute a legitimate site of knowledge expertise. Finally, a hallmark of feminist scholarship and pedagogy is its commitment to contesting traditional views of research, teaching, and learning. The qualification of this broad claim would be discipline and context specific, but it does rely on the recognition that the patriarchal character of the academy has long perpetuated the notion that 'knowledge and teaching methods can be value-free' (Webb et al. 2002: 418).

5 Here I follow the second of Terry Anderson's Three generations of distance pedagogy (Anderson \& Dron 2011) and locate feminist pedagogy within a social constructivist paradigm. 
As can be seen by the six principles elucidated above, feminist pedagogy in the study of religion is not only the purview of scholars who research and teach on topics of gender or sexuality ${ }^{6}$. Indeed, the renewed focus on decoloniality in research and teaching, in large part due to the demands of student activists to decolonized education in South Africa, is further evidence that an awareness of powers' constitutions and operations, and a desire to serve and empower students, can be considered generally applicable in all disciplines and fields of study.

In the context of decolonial approaches to the study of religion, professor of Religion in Africa, Adriaan van Klinken (2019) offers a proposal for a decolonial approach to religion that reflects the values of feminist pedagogies while following the core principles of decolonial thinking. First, he advocates for a commitment to pluriversity as a research orientation, which encompasses epistemic diversity. Second, he argues for the acknowledgement of partiality as a co-constituent of knowledge production, and lastly, he suggests a commitment to participatory work, which includes 'greater honesty and transparency about the ways in which we negotiate in our work questions of political engagement, of personal commitment to the causes, communities and subjects we study, and of implicit and explicit normative judgement' (Van Klinken 2019:152). As illustrated, the pedagogical injunctions of feminist scholarship can support the more recent calls for decolonization in the academy in tangible ways.

\section{The Reading Group}

The ReligioTheo reading group was inspired by my own experiences as a $\mathrm{PhD}$ candidate in Religious Studies. Over the course of three years, once a week for about two hours, I participated in a weekly reading group hosted by a senior professor. Together with my co-readers, we engaged an eclectic intellectual smorgasbord, including Immanuel Kant, Ludwig Wittgenstein,

6 Having said this, in the study of religion, scholars of gender and religion have established the basis for other scholars in the field to engage feminist pedagogies in teaching and research practices. For more detailed descriptions of the important work that has already been done, especially at postgraduate level, see Nadar, Reddy, Van der Walt, Siwlia, Gerle (2014), Nadar and Reddy (2016), and Seedat and Nadar (2020). 
Karl Marx, Steven Biko, Hannah Arendt, Talal Asad, and Saba Mahmood. While there was some level of flexibility and input from the group was often considered, it was obvious that the professor had more or less a clear vision of the group's reading direction and this was aligned to the goals of long-term projects for which he was the principal investigator. The discipline of reading in preparation for discussion with a group of peers was an important part of my own postgraduate experience and instilled a deep appreciation for the practice of reading in a community.

Having spoken with students in the research center, there was a consensus that they wanted to read more widely and in a focused manner. The students agreed that reading in community would provide opportunities for peer support and accountability that reading on their own did not offer. Many wanted to read beyond the confines of their theologically oriented undergraduate degree training. The students also expressed a desire to recreate the sense of community that they felt during their quarterly cohort supervision workshops on a more regular basis.

While all decision-making about the direction of the group would be collaborative, I made one request for an open-ended short written response to the reading to be shared with colleagues, prior to meeting for discussion. The rationale would enable us to ground our discussions and provide insight into the unique perspective of each group member. This writing practice was also evidence of the good-faith effort that the group would make to carefully read and consider the agreed upon text. Furthermore, we committed to attend every session (these were all virtual), although there was the understanding that once or twice per term, we might not be able to make it. We envisioned the group to be a space to share ideas about specific texts but agreed that we would allow things to develop organically, to follow our thoughts and allow for a level of flexibility that would match our shifting interests. We discussed the potential of other developmental opportunities such as dedicated reading group sessions to working on the development of academic writing skills. When the pandemic thwarted the original plans of the group, the decision to shift to an online environment was unanimous. According to students, the group offered the kind of intellectual and psycho-social support that was both timeless and timely. 


\section{Learning Outcomes}

As a result of the voluntary status of the group, the learning outcomes could be determined through collaboration and conversation, further enhancing its commitment to feminism. After a few sessions and once the decision to produce a podcast was made, the learning outcomes were reviewed again. The first learning outcome was the production of new knowledge about religion. This would take place through group members offering their insights, opinions, lived experiences, theorization, and analyses of a variety of texts in the disciplines of religion and theology. Here we embraced a generative and expansive approach to knowledge production. Leading religious studies scholar, David Chidester (2013) explains how postgraduate students could produce new knowledge in the study of religion. He suggests that,

by engaging in the alchemy of theory and data - in which theory without data is empty, but data without theory is blind - they must produce something original... New knowledge is not produced out of merely looking at something, but requires theoretically informed and methodologically rigorous engines of argumentation, interpretation, explanation, or analysis (Chidester 2013:6).

The second learning outcome was that students had to work collaboratively and non-hierarchically. This is an important feature of the democratic feminist classroom. This does not mean that leadership was not present, but rather that leadership responsibilities were shared, rotated, discussed, and used in a functional as opposed to didactic or authoritarian way (Nadar \& Reddy 2015). A third outcome was for students to develop and expand on a variety of 'soft skills' related to academia, including chairing, scribing, and facilitation. The fourth learning outcome being technical proficiency in knowledge production practices, was a direct consequence of the adoption of the podcasting model. Hess and Macomber (2020:208), in their rationale for using documentary film production as a feminist teaching technique, explain that the technical skills gained from non-traditional pedagogical practices, 'expand feminist teaching to meet our contemporary culture'.

Following the work of Nadar and Reddy (2015), I took the position that knowledge production and the processes thereof are just as important as the content or the production of the research product. The myriad of complex ways in which the pandemic has shifted and transformed research landscapes 
and practices of knowledge production and circulation, cannot be underestimated. It is too early to tell the extent of the consequences that the pandemic has had on the knowledge economy. However, the earnest embracing of technology by universities in hitherto imaginative and unexplored techniques as a result of the pandemic has certainly expanded the scope for intellectual collaboration and knowledge circulation across time and space. While the use of media for teaching has become commonly accepted within many disciplines, the production of multimedia content as a pedagogical process and tool has received less attention.

\section{Podcasts and the Study of Religion}

The popularity of the podcast has dramatically increased in recent years, and the context of the pandemic has further accelerated its ubiquity. Recent advances in technology have made podcasts easier to produce, circulate, and access than other media products and applications. Podcasts are audio-only files which are cheap to produce and asynchronous in character, allowing for mobility and multi-sensorial consumption. The nature of technology means that it does not consume nearly as much bandwidth as media content and can be downloaded quickly and consumed at a later stage. The start-up costs for both production and consumption of podcasts are limited to the possession of a mobile digital device and access to the internet. While for the general population access to these tools of technological engagement and inclusion remains deeply unstable and uneven as a result of socio-economic disparities that disproportionately disadvantage both urban poor and rural communities, in higher education, there is evidence to suggest that podcasts may offer a more inclusive experience of teaching technology for students from various backgrounds. Through a quantitate survey conducted at a historically disadvantaged South African higher education institution, Gachago, Livingston, and Ivala (2016:860) found that, despite severe resource constraints and fear of technology among both lecturers and students, the simplicity and accessibility of podcasts promise a successful mainstream adoption of a low-threshold technology for African higher education.

Podcasting as an educational tool has been studied in a number of disciplines, including human geography (Kinkaid, Brain, \& Senanayake 2019), social sciences (Vajoczki, Watt, Marquis, \& Holshausen 2010), and 
education (Kay 2012). These studies explain and analyze the undergraduate student consumption of podcasts and its effect on their experiences of teaching and learning, and hypothesize the potential that podcasts have for replacing traditional lectures and lecturers. What is missing from the literature on podcasts and scholarship is a reflection on the process of production of a podcast with students and teachers as co-producers of knowledge. The lacuna of literature on this particular iteration of podcasting education, potentially further affirms the innovative albeit experimental nature of the ReligioTheo podcast. The production of a podcast about religion from a black collective of emerging scholars studying and researching religion from a non-confessional perspective, is significant for the representation of the epistemic diversity that it brings, and contests the 'Western, Eurocentric, colonialist and racialized models' that have dominated the study of religion and predetermined what constitutes authentic knowledge production and circulation in the field (Van Klinken 2019).

While there are many podcasts available on religion, across a variety of platforms, and many podcasts on the study of religion and theology from scholars working and located in the global north, there are none from the South African context or the African continent. Scholars have long argued that the media are a site of knowledge about religion and for knowledge production about religion (Hackett \& Soares 2014; Eisenlohr 2012; Engelke 2010). Given the possibilities for community creation and opportunities for teaching and learning that podcasts offer, these may be considered important emerging sites for encountering and producing knowledge about religion and religious diversity. In this sense, podcasts are media where we can learn about religions and religious diversity through studying the content. Through the production of our own content and its circulation as media, it is also a place where we can discuss what we have learned through studies of both offline and online content about religion.

The pre-production aspects of developing any multimedia content includes standard academic skills such as research and writing, but also extends to critical thinking, creativity, and collaboration. In podcasting, as with other media techniques such as film, the voice of the speaker is the medium, and so effective communication is critical. The fact that the spoken voice is the medium of knowledge delivery, has the potential to change the way in which knowledge, especially that which is considered academic, is received and accessed (Hess \& Macomber 2021). If the correct context is 
scripted, then the spoken language can be far less formal and impenetrable than written academic language. Furthermore, the format of a podcast allows for dialogue and discussion to take place. When one or more persons are engaged in a discussion, then an intentionally managed podcast episode can become a democratic feminist classroom that is conducive to multi-directional learning and teaching.

\section{Making Lemons out of Lemonade: Podcasting in a Pandemic}

Creating a podcast became a natural progression of the group. We were recording the discussion sessions for our records and for our colleagues who were unable to attend. After about six meetings we decided that we wanted to shift from reading individual articles and chapters to reading a full text. Given the diverse interests of the groups, we have students studying religion and media, race, gender and sexuality, African Traditional Religions, and religion and popular culture, it was a challenge to settle on a text to read. Given the context of a pandemic and its accompanying heaviness, we agreed that we wanted to read something a little 'lighter'. The group acknowledged and sought to resist afro-pessimistic attitudes that project the expectation that African scholars should primarily engage in research that addresses or seeks to resolve the serious issues that affect the continent, despite the fact that Africa and Africans have been and remain the primary research subjects of non-Africans for centuries (Hountondji 2009; Olukoshi 2006).

The final decision on what to read was somewhat whimsical, although not arbitrary. One of the group members, Dr Megan Robertson suggested The Lemonade Reader. This is a collection of essays edited by Kinitra Brooks and Kameelah Martin and focuses on the iconic Lemonade album produced and performed by celebrity artist, Beyoncé Knowles. To be clear, not all the group members formed part of the BeyHive (the colloquial term for Beyoncé's fans), although some, including myself, consider themselves fans. One member of the group had never listened to a single song by Beyoncé, while another declared indifference but curiosity that a celebrity could be the focus of an extended academic text. After a few discussions, preliminary reading, and internet-based research by individual members, we decided that The Lemonade Reader, together with the audio-visual album by the same name, and Beyoncé's own superhuman status, were interesting subjects for our first podcast recording as a group. This vital pre-production 
stage also allowed for us to discern some of the intersections that our own work and locations shared with that of the texts that would be discussed.

Before engaging the text, which comprises a collection of essays and editorials, we listened to the album and noted issues about gender, race, black men and women's sexuality, feminism, African-American spiritual traditions, and African Traditional Religion. Power and agency were entangled in the lyrical and visual world that Beyoncé had constructed through the album, and which resonated with aspects of our own contexts and research interests. Prior to recording, the members would either circulate a written text that covered the main points of their offering, or we would have a pre-recording meeting where we discussed the text and gave the lead readers for that episode a chance to soundboard their ideas. The pre-recording sessions were not compulsory for everyone to attend, but rather functioned like ad hoc committees that offered those leading the session the opportunity to purge pre-production jitters.

The book featured three parts and each part consisted of five to six chapters. Each student would take responsibility for one or two chapters per part. Each co-reader's voice is heard, offering a reflection on the reading. The rest of the group would pose questions or elaborate on the points raised. Since the group already had experience of discussing texts together, they were familiar conversation partners and did not find it difficult to engage each other. The group dynamic was pleasant and there were no major personality clashes, despite the diversity of the group in terms of research interests and social locations. In large part, this is due to the pre-existing relationships that were formed in the context of the research center and the prior reading group meetings that had taken place.

Despite making technical proficiency a learning outcome, we soon realized that the process of post-production would be too labor intensive to manage on my own and I did not want to unduly burden students with overly time-consuming activities after the major intellectual work of the project was completed. I decided to enlist the help of a multimedia production company to assist with the editing process. In order for editing to take place, the recordings would need to be transcribed and this was outsourced and paid for from a budget that had been set aside for a reading group retreat that could not take place due to Covid-19 restrictions. Through the editing process, almost twelve hours of recordings were edited to approximately three hours of listening time. 
In a post-production conversation, we tried to make sense of how we could collectively maintain ownership of the research product and our experiences while producing scholarship about it. From the outset I was clear that I would need to produce an academic article in order to meet accountability standards set for academics in our faculty. Since the project was an experiment in co-production, we agreed that we could each reflect on our experiences of its production and that if we decided to analyze our conversations for research purposes, we would first seek the permission of the collective ${ }^{7}$. Furthermore, we agreed in good faith to inform each other of where the work traveled. All members of the reading group agreed that they would like to produce another set of conversations in this style. This unexpected and heartening outcome agrees with Webb et al. (2004), that '[p]erhaps the major collegial benefit of a feminist research group is the potential for the development of meaningful, long-term collegial relationships'. The context of the ReligioTheo podcast project, a global health pandemic, could potentially have been its greatest challenge. Under these new circumstances, and given its voluntary status, it would have been understandable if not expected for its activities to pause, let alone expand in scope and ambition. The commitment of the group members may be indicative of its collaborative nature, including the intentional co-production and co-ownership of the research product.

It is too early and beyond the scope of this article to assess the success of the podcast as a pedagogical tool outside of this group setting. However, beyond the technical issues and the underestimation of how much pre- and post-production time would be needed, the feminist pedagogy learning outcomes of the project were achieved. The six principles of feminist pedagogy that have structured my approach to teaching as a feminist scholar of religion, were maintained as both terms of reference as well as guides for practice. Once the podcast is circulated to a broader audience, more data will

7 This is mostly why this article has not included a reflection on the experiences of the other participants and has mainly focused on my engagement with the process of facilitating its production. Given our emphasis on co-production and the underlying philosophy that all students are knowledge producers in their own capacities, it was agreed that we would all maintain the right to share our own experiences in this project first. 
be produced, and this may propel a different kind of analysis to that which is offered in this article.

\section{Conclusion}

In conclusion, this article is certainly not providing a prototypical guide for how to facilitate learning in a pandemic. In sharing my experiences as a scholar and pedagogue during the pandemic, this essay contains a modest call for scholars of religion, irrespective of our research orientations, to consider how we are facilitating knowledge production with students during this time. While over a year has passed since the first national lockdown in South Africa, given the ongoing status of the pandemic, controversy surrounding the acquisition and distribution of a vaccine, the effects of the economic fallout on the livelihoods of millions of South Africans, the pre-emptive, protective restrictions regarding social activities which preclude the possibilities of collective grieving at a time when death is a constant companion, and the sustained intensity of the shadow pandemic of gender-based violence, it is both difficult and hubris to make firm claims regarding the possibilities that any pedagogical interventions may yield. Instead, the uncertainty of these times requires that our orientation towards teaching and learning remains as flexible as possible. If there was ever a time to revise how we teach, supervise, and produce knowledge, the pandemic has compelled us to do just that. It is my hope that this reflection on a feminist pedagogical experiment and the argument for the consideration of the wisdom that feminist approaches to research and attaching may offer, especially in times of crisis, might deepen our understanding and capacity to respond to our students' changing needs within and beyond the conditions of this global health catastrophe.

\section{References}

Adams, C. \& E. Rose 2014. Will I ever connect with my students? Online teaching and the pedagogy of care. Phenomenology and Practice 8, 1: 5-16. doi: 10.29173/pandpr20637

Ali, K., J. Watts Belser, G.Y. Kao, \& S.T.J. Smith 2020. Living it out: Feminism during Covid-19. Journal of the Feminist Studies in 
Religion 36, 2: 107-116. URL: https://www.jstor.org/stable/10.2979/ jfemistudreli.36.2.08

Anderson, T. \& J. Dron 2011. Three generations of distance education pedagogy. The International Review of Research in Open and Distributed Learning, 12, 3: 80-97. doi: https://doi.org/ 10.19173/irrodl.v12i3.890

Berkhout, S.G. \& L. Richardson 2020. Identity, politics, and the pandemic: Why is Covid-19 a disaster for feminism(s)? History and Philosophy of the Life Sciences 42, 4: 1-6. doi: https://doi.org/10.1007/s40656020-00346-7

Bhana, D., R. Morrell, T., Shefer, \& S. Ngabaza 2010. South African teachers' responses to teenage pregnancy and teenage mothers in schools. Culture, Health and Sexuality: An International Journal for Research, Intervention and Care 12, 8: 871-883. doi: https://doi.org/ 10.1080/13691058.2010.500398

Chidester, D. 2013. Postgraduates producing knowledge. Journal for the Study of Religion 26, 1: 5-7.

Clark, B. 2020. Gender-based violence and Covid-19 in South Africa: The clash of pandemics. LexisNexis. Available at: https://www. lexisnexis.co.za/_data/assets/pdf_file/0005/820373/LN_ROL_CAF E_White_Paper_20201202.pdf. (Accessed on May 7, 2021.)

Desmond Tutu Centre Annual Report. 2020. Desmond Tutu Centre for Religion and Social Justice Annual Report. Available at: https:// desmondtutucentre-rsj.uwc.ac.za/publications/\#annualreports. (Accessed on June 14, 2021.)

Eisenlohr, P. 2012. Media and religious diversity. Annual Review of Anthropology 41, 1: 37-55. doi: http://dx.doi.org/10.1146/annurevanthro-092611-145823

Engelke, M. 2010. Religion and the media turn: A review essay. American Ethnologist 37, 2: 371-379. URL: https://www.researchgate.net/ publication/44207151 Religion and the Media Turn A Review E ssay

England, K.V. 1994. Getting personal: Reflexivity, positionality, and feminist research. The Professional Geographer 46, 1: 80-89. doi: https:// doi.org/10.1111/j.0033-0124.1994.00080.x

Fidler, D.P. 2020. Vaccine nationalism's politics. Science 369, 6505: 749. doi: $10.1126 /$ science.abe 2275 
Gachago, D., C. Livingston, \& E. Ivala 2016. Podcasts: A technology for all? British Journal of Educational Technology 47, 5: 859-872.

Hackett, R.I.J. \& B.F. Soares (eds.) 2014. New media and religious transformations in Africa. Bloomington: Indiana University Press. URL: https://www.new-directions.sps.ed.ac.uk/hackett-soares-edsnew-media-religious-transformations-africa/

Hames, M.M.P. 2016. Black feminist intellectual activism: A transformative pedagogy at a South African university. PhD thesis, African Gender Institute, University of Cape Town, Cape Town.

Hess, A. \& K. Macomber 2020. My parents never read my papers, but they watched my film: Documentary filmmaking as feminist pedagogy. Gender and Education 33, 3: 306-321. doi: https://doi.org/10.1080/ 09540253.2020 .1763921

Ho, H. \& I. Dascalu 2020. Global disparity and solidarity in a pandemic. Hastings Center Report 50, 3: 65-67. doi: 10.1002/hast.1138

Hountondji, P.J. 2009. Knowledge of Africa, knowledge by Africans: Two perspectives on African studies. Revista Crítica de Ciências Sociais 1, 1. doi: 10.4000/rccsar. 174

Jandrić, P. 2020. Postdigital research in the time of Covid-19. Postdigital Science and Education 2: 233-238. doi: https://doi.org/10.1007/ s42438-020-00113-8

Jandrić, P. \& S. Hayes 2020. Writing the history of the present. Postdigital Science and Education 2: 1062-1068. doi: https://doi.org/10.1007/ s42438-020-00168-7

Juhasz, A., L. Wexler, L. Losh, \& S. Irish 2020. Feminist pedagogy in a time of Coronavirus pandemic. Cuny Academic Works. URL: https:// academicworks.cuny.edu/bc pubs/261/

Kay, R. 2012. Exploring the use of video podcasts in education: A comprehensive review of the literature. Computer in Human Behaviour 28, 3: 820-831. doi: https://doi.org/10.1016/j.chb.2012.01.011

Kinkaid, E., K. Brain, \& N. Senanayake 2019. The podcast-as-method? Critical reflections on using podcasts to produce geographic knowledge. Geographical Review 110, 10: 78-91. doi: https:// doi.org/10.1111/gere.12354

Lewis, H. 2020. The Coronavirus is a disaster for feminism: Pandemics affect men and women differently. Available at: https://www.theatlantic. 
com/international/archive/2020/03/feminism-womens-rightscoronavirus-covid19/608302/. (Accessed on May 7, 2021.)

Meraviglia, C. \& A. Dudka 2020. The gendered division of unpaid labor during the Covid-19 crisis: Did anything change? Evidence from Italy. International Journal of Sociology 51, 1: 64-75. doi: https:// doi.org/10.1080/00207659.2020.1832346

Moorhouse, B. \& M.C. Tiet 2021. Attempting to implement a pedagogy of care during the disruptions to teacher education caused by COVID19: A collaborative self-study. Studying Teacher Education. doi: 10.1080/17425964.2021.1925644

Nadar, S. \& S. Reddy 2015. God's justice is social justice: Exploring African feminist theologies in a Master's programme at two South African higher education institutions. The Ecumenical Review 67, 4: 591-606. doi: 10.1111/erev.12193

Nadar, S. \& S. Reddy 2016. From instrumentalization to intellectualization: Response to silent scripts and contested spaces. Journal of Feminist Studies in Religion 32, 1: 136-142. doi: 10.2979/jfemistudreli.32.1.15

Nadar, S., S. Reddy, C. Van der Walt, L. Siwlia, \& E. Gerle 2014. 'Flourishing guinea pigs': Exploring intersectionality and interdisciplinarity in a master's programme on gender, religion and health at two South African universities. The Journal for Gender and Religion in Africa 20, 2: 203-230.

Newham, G. \& A. Du Plessis 2020. How might the Covid-19 lockdown affect public safety in SA? Available at: https://issafrica.org/isstoday/how-might-the-covid-19-lockdown-affect-public-safety-in-sa. (Accessed on May 7, 2021.)

Olukoshi, A. 2006. African scholars and African studies. Development in Practice 16, 6: 533-544. doi: 10.1080/09614520600958116

Reichelt, M., K. Makovi, \& A. Sargsyan 2021. The impact of Covid-19 on gender inequality in the labor market and gender-role attitudes. European Societies 23: S228-S245. doi: https://doi.org/10.1080/ 14616696.2020.1823010

Seedat, F. \& S. Nadar 2020. Between boundaries, towards decolonial possibilities in a feminist classroom: Holding a space between the Qur'an and the Bible. Religion \& Theology 27: 229-249. doi: 10.1163/15743012-02703003 
Shrewsbury, C. 1987. What is feminist pedagogy? Women's Studies Quarterly 15, 1: 6-14. URL: https://www.jstor.org/stable/40003432

Vajoczki, S., S. Watt, N. Marquis, \& K. Holshausen 2010. Podcasts: Are they an effective tool to enhance student learning? A case study. Journal of Educational Multimedia and Hypermedia 19, 3: 349-362. URL: https://www.learntechlib.org/p/30510/

Van Klinken, A. 2019. Studying religion in the pluriversity: Decolonial perspectives. Religion 50, 1: 148-155. doi: https://doi.org/10.1080/ 0048721X.2019.1681108

Walker-Gleaves C. 2019. Is caring pedagogy really so progressive? Exploring the conceptual and practical impediments to operationalizing care in higher education. In Gibbs P. \& A. Peterson (eds.): Higher education and hope. Cham: Palgrave Macmillan. doi: https://doi.org/10.1007/978-3-030-13566-9_5

Webb, L.M., M.W. Allen, \& K.L. Walker. 2002. Feminist pedagogy: Identifying basic principles. Academic Exchange Quarterly 6, 1: 6772.

Webb, L.M., K.L. Walker, \& T.S. Bollis 2004. Feminist pedagogy in the teaching of research methods. International Journal Social Research Methodology 7, 5: 415-428.

Wigginton, B. \& M.N. Lafrance 2019. Learning critical feminist research: A brief introduction to feminist epistemologies and methodologies. Feminism \& Psychology 0, 0: 1-17. doi: https://doi.org/10.1177/ 0959353519866058

Dr Lee-Shae Salma Scharnick-Udemans Desmond Tutu Centre for Religion and Social Justice University of the Western Cape lscharnickudemans@uwc.ac.za 